\title{
Nutritional and Environmental Influences on Autism Spectrum Disorder
}

\author{
Geir Bjørklund $^{1^{*}}$ and Max Chartrand ${ }^{2}$ \\ ${ }^{1}$ Council for Nutritional and Environmental Medicine, Mo i Rana, Norway \\ ${ }^{2}$ DigiCare Behavioral Research, Casa Grande, AZ, USA
}

*Corresponding author: Geir Bjørklund, Council for Nutritional and Environmental Medicine, Toften 24,8610 Mo i Rana, Norway, Tel: +47 75 13 03 71; E-mail: bjorklund@conem.org

Rec date: February 27, 2016; Acc date: February 29, 2016; Pub date: March 07, 2016

Copyright: (c) 2016 Bjørklund G, et al. This is an open-access article distributed under the terms of the Creative Commons Attribution License, which permits unrestricted use, distribution, and reproduction in any medium, provided the original author and source are credited.

\section{Editorial}

Autism spectrum disorder (ASD) is a neurodevelopmental disorder characterized by pervasive deficits in social interaction, impairment in verbal and non-verbal communication, and stereotypical patterns of interests and activities. ASD can be extremely costly to society at large and the individuals and families involved, constituting one of the most perplexing challenges in child development and education.

The prevalence of children with ASD continues to increase all over the world. Current estimates in the US are one child in 45 has a diagnosis of ASD [1]. ASD has a multifactorial etiology involving interactions between genes, environment, and diet [2]. ASD is almost five times more common among boys than girls [3].

Mercury $(\mathrm{Hg})$ is a neurotoxicant, and potentially one of the main environmental triggers for ASD [4]. Children are exposed to $\mathrm{Hg}$ via maternal amalgam fillings (as infants and later from the mother milk), thiomersal (an organomercury compound used as a vaccine preservative), compact fluorescent light bulbs (containing $\mathrm{Hg}$ ), commercial and freshwater fish, industrial pollutants, etc.

Neuroinflammation, with increased levels of neurokinin A (a proinflammatory neuropeptide), is seen in some children with ASD, and may be caused by elevated blood-Hg levels. In fact, a recent study found a positive relationship between the Childhood Autism Rating Scale (CARS) scores and the levels of both serum neurokinin A and blood-Hg [4].

The original studies on the potential relationship between $\mathrm{Hg}$ and ASD has been investigated from 1999 to 2015 [5]. It was found that $86 \%$ of research papers with public health and/or industry affiliation reported no relationship between $\mathrm{Hg}$ and $\mathrm{ASD}$. However, among studies without public health and/or industry affiliation, only 19\% found no connection between Hg and ASD [5]. The discrepancy in these results suggests a bias indicative of a conflict of interest.

Research indicate that children with ASD appear to be at risk of zinc $(\mathrm{Zn})$ deficiency, copper $(\mathrm{Cu})$ toxicity, and often disturbed metallothionein (MT) system functioning [6-8]. Mercury accumulation may occur as a cause or consequence of MT dysfunction in ASD children, which may be one of the causes of $\mathrm{Zn}$ deficiency. Zinc and $\mathrm{Cu}$ are both antagonists in function, and essential for living cells. Therefore, it is important to monitor and follow the values for both trace elements together during Zn therapy [6-8].

There is growing evidence for a gut-brain connection in ASD. This suggests a potential benefit for digestive enzyme therapy for children with ASD. In a recent study, ASD children that were given digestive enzyme therapy for three months showed significant improvement in emotional response, general impression autistic score, general behavior, and gastrointestinal symptoms [9].

Glycosaminoglycans (GAGs) is a family of linear sulfated polysaccharides that are associated with central nervous system development, maintenance, and disorders in humans. Since GAGs can be somewhat modulated by diet, the role of GAGs levels were in a recent study compared in ASD children and normal controls [2]. It was found that the total GAG concentration was significantly higher in urine samples of ASD children than in the controls, and that a 90-day elimination diet (casein-free, Special carbohydrates, and multivitamin/ mineral supplements) significantly reduced the urinary GAG levels in ASD children [2].

The relationship between vitamin D and ASD has been studied, and markedly lower vitamin D levels have been found in ASD children compared with healthy children [10]. In fact, the vitamin D levels had a significant negative correlation with CARS scores. Improved outcome was found in the CARS scores of the ASD children when taking $300 \mathrm{IU}$ vitamin D3/kg/day (not to exceed $5000 \mathrm{IU} /$ day) for three months [10].

Vested interests to the contrary and their political counterparts must join with independent researchers in finding ways to eliminate and/or reduce neurotoxic exposure to heavy metals, perchlorates, and other environmental and food toxins. Thiomersal should be totally banned for use in vaccines.

Nutrient therapy can be very potent and has minimal to no side effects, since no molecules foreign to the body are needed [2]. Nutritional deficiencies should be considered for all children so that they may develop optimally and thereby head off developmental delays.

Moreover, for all children exhibiting developmental disorders, we feel that safe, inexpensive oral chelating therapies can be instituted. Each case will require some level of clinical analysis to determine the best approach $[11,12]$.

\section{References}

1. Zablotsky B, Black LI, Maenner MJ, Schieve LA, Blumberg SJ (2015) Estimated Prevalence of Autism and Other Developmental Disabilities Following Questionnaire Changes in the 2014 National Health Interview Survey. Natl Health Stat Report (87): 1-20.

2. Endreffy I, Bjørklund G, Dicső F, Urbina MA, Endreffy E (2016) Acid glycosaminoglycan (aGAG) excretion is increased in children with autism spectrum disorder, and it can be controlled by diet. Metab Brain Dis 31: 273-278. 
Citation: Bjørklund G, Chartrand M (2016) Nutritional and Environmental Influences on Autism Spectrum Disorder. J Nutr Disorders Ther 6: e123. doi:10.4172/2161-0509.1000e123

Page 2 of 2

3. Bertrand J, Mars A, Boyle C, Bove F, Yeargin-Allsopp M, et al. (2001) Prevalence of autism in a United States population: the Brick Township New Jersey, investigation. Pediatrics 108: 1155-1161.

4. Mostafa GA, Bjørklund G, Urbina MA, Al-Ayadhi LY (2016) The levels of blood mercury and inflammatory-related neuropeptides in the serum are correlated in children with autism spectrum disorder. Metab Brain Dis.

5. Kern JK, Geier DA, Deth RC, Sykes LK, Hooker BS, et al. (2015) Systematic assessment of research on autism spectrum disorder and mercury reveals conflicts of interest and the need for transparency in autism research. Sci Eng Ethics.

6. Bjørklund G (2013) The role of zinc and copper in autism spectrum disorders. Acta Neurobiol Exp (Wars) 73: 225-236.

7. Li SO, Wang JL, Bjørklund G, Zhao WN, Yin CH (2014) Serum copper and zinc levels in individuals with autism spectrum disorders. Neuroreport 25: 1216-1220.
8. Macedoni-Luksic M, Gosar D, Bjørklund G, Orazem J, Kodric J, et al. (2015) Levels of metals in the blood and specific porphyrins in the urine in children with autism spectrum disorders. Biol Trace Elem Res 163: 2-10.

9. Saad K, Eltayeb AA, Mohamad IL, Al-Atram AA, Elserogy Y, et al. (2015) A Randomized, Placebo-controlled Trial of Digestive Enzymes in Children with Autism Spectrum Disorders. Clin Psychopharmacol Neurosci 13: 188-193.

10. Saad K, Abdel-Rahman AA, Elserogy YM, Al-Atram AA, Cannell JJ, et al. (2015) Vitamin D status in autism spectrum disorders and the efficacy of vitamin D supplementation in autistic children. Nutr Neurosci.

11. Bjørklund G (2015) Clinical use of the metal chelators calcium disodium edetate, DMPS, and DMSA. Saudi J Kidney Dis Transpl 26: 611-612.

12. Bjørklund G (2015) Selenium as an antidote in the treatment of mercury intoxication. Biometals 28: 605-614. 